\title{
Anaemia Prevalence Pattern among Pregnant Women in India -An Analysis of National Family Health Survey-IV
}

\author{
Ajit Kumar Dey ${ }^{1}$ \\ 1Department of Community Medicine, Silchar Medical College, Silchar, Assam, India.
}

\section{ABSTRACT}

\section{BACKGROUND}

Globally, anaemia affects 1.62 billion people, which corresponds to $24.8 \%$ of the population. Anaemia in India is recognized as a severe public health problem based on the population-specific $\mathrm{Hb}$ threshold value $\geq 40 \%$. Data from NFHS 2, 3, and 4, indicated that about 50 percent of pregnant women in India were anaemic and among the South Asian countries, India has the highest prevalence of anaemia in pregnancy. The present analysis of NFHS 4 survey data is undertaken to understand the anaemia prevalence pattern in India and important factors contributing to it.

\section{METHODS}

The present analysis has been carried out by using NFHS 4 survey datasets conducted during the year 2015-16 among 32,428 women aged 15 - 49 years who were pregnant during or within 5 years before survey. The data analysis was performed in SPSS version 22 .

\section{RESULTS}

The mean age of pregnant women was 24.7 years \pm 4.874 . Majority ( 72.7 percent) of women was in the age group 20-29 years; the average age at $1^{\text {st }}$ birth was $20.9 \pm$ moderately, 23.7 percent mildly anaemic and remaining 50.4 percent were without anaemia. The mean haemoglobin level among the pregnant women is $10.9 \mathrm{~g} / \mathrm{dL}$. Interstate variation was observed in anaemia prevalence.

\section{CONCLUSIONS}

The present observation will add to our knowledge and helps in designing interventions addressing the different dimensions of anaemia prevalence. 3.383 years. 1.4 percent of pregnant women were severely anaemic, 24.5 percent

Corresponding Author: Ajit Kumar Dey, Assistant Professor, Department of Community Medicine, Silchar Medical College, Silchar-788014, Assam, India. E-mail:drajit.smc@gmail.com

DOI: $10.14260 / \mathrm{jemds} / 2020 / 402$

Financial or Other Competing Interests: None.

How to Cite This Article:

Dey AK. Anaemia prevalence pattern among pregnant women in India-an analysis of national family health surveyIV. J. Evolution Med. Dent. Sci. 2020;9(25): 1842-1848, DOI: $10.14260 /$ jemds/2020/402

Submission 28-01-2020, Peer Review 22-05-2020, Acceptance 29-05-2020, Published 22-06-2020.

\section{KEY WORDS}

Anaemia, States, Prevalence, Pregnant, Women 


\section{BACKGROUND}

Globally, anaemia affects 1.62 billion people, which corresponds to $24.8 \%$ of the population, among which 56 million are pregnant women. As per estimates based on data from the WHO Global Database on anaemia, its prevalence among the pregnant women is 41.8 percent in the world and 48.2 percent in South East Asia region. ${ }^{1}$ The anaemia prevalence in India is recognized as a severe public health problem of public health significance based on the population-specific $\mathrm{Hb}$ threshold value $\geq 40 \%{ }^{2}$ The most significant contributor to the onset of anaemia is iron deficiency. It is assumed that $50 \%$ of the cases of anaemia are due to iron deficiency. ${ }^{3}$

From metanalysis study conducted in low- and middleincome countries there is evidence of high prevalence of maternal anaemia during pregnancy in low income countries especially in African and Asian regions ${ }^{4}$ probably because of high prevalence of malaria and poor nutrition including underweight and iron deficiency. Iron deficiency anaemia increases a woman's risk of dying from cardiac failure in childbirth. Compared with other forms of malnutrition included among the 26-risk factors in GBD 2000, iron deficiency anaemia ranks \#9 overall in terms of DALYs lost. ${ }^{5}$ The India State Level Disease Burden Initiative has reported a varied epidemiological transition across the states of India since 1990 as part of Global Burden of Diseases. ${ }^{6}$

Anaemia increases the risk of adverse birth outcomes and mortality during and after childbirth and leads to poor cognitive and physical development and mortality in children. ${ }^{7}$ There is intricate relationships exists between economic, political, demographic, sociocultural and biological factors that influence the patterns of underlying causes, vulnerability to, and distribution of anaemia severity and consequences. $^{8}$

There was a substantial reduction both in the prevalence and severity of anaemia across all States over the last 15 years period between DLHS 2 and DLHS 4 and AHS CAB; the magnitude of decline was higher in States with better antenatal care coverage. ${ }^{9}$

In 2017, India released the National Nutrition strategy, which outlined measures to address malnutrition across the life cycle. ${ }^{10}$ The 2025 target is to reduce anaemia prevalence in women of reproductive age by $50 \%$ from an estimated baseline prevalence of $30.3 \%$ in 2012,2

Eliminating malnutrition in all its forms is imperative to break the intergenerational cycle of poverty, and reach the Sustainable Development Goals by 2030. In April 2016, the UN General Assembly proclaimed 2016 to 2025 the United Nations Decade of Action on Nutrition. It aims to provide a clearly-defined time-bound cohesive framework that works within existing structures and available resources and promote coherence of national, regional and international policies focusing on evidence and results across multiple sectors to combat all forms of malnutrition.

Over this background, the present analysis of NFHS 4 survey data is undertaken with the aim to understand the anaemia prevalence pattern in India and important factors contributing to it. The following are the specific objectives.

\section{Objectives}

1. To assess the socio-demographic profiles of currently pregnant women in India.

2. To assess the prevalence of anaemia among the pregnant women in India and the association with different sociodemographic variables.

3. To assess the anaemia prevalence pattern in major states of India and the association of different factors.

\section{METHODS}

The present analysis has been carried out by using NFHS 4 survey datasets conducted in 29 states and 6 union territories of India during the year 2015-16. Before the present study was undertaken due permission from DHS program was taken for using the datasets.

\section{Study Universe}

32,428 women aged 15-49 years who were pregnant during or within 5 years of before survey.

\section{Variable Selection}

Variables related to socio-demographic characteristics such as place of residence, religion, educational attainment, wealth index, fertility variables such as marriage, number of children, practice of family planning methods etc.

\section{Description of Variables \\ Wealth Index}

The socioeconomic status has significant influence on prevalence of anaemia as evidenced from several studies from different parts of the world. ${ }^{8,11}$ In NFHS surveys, a composite index called wealth index is used for classifying families based on data collected in the Household Questionnaire concerning questions on availability of consumer items such as television, car; dwelling characteristics such as flooring material; type of drinking water source; toilet facilities; etc. 12

\section{Haemoglobin Measurement}

In NFHS-4 was performed using the HemoCue photometer (Hb 201+). ${ }^{13}$ Classification of anaemia done according to the WHO grading, pregnant women with $\mathrm{Hb}$ levels $\geq 11 \mathrm{~g} / \mathrm{dL}$ as non-anaemic, between 10.0 and $10.9 \mathrm{~g} / \mathrm{dL}$ as mild anaemic, between 7.0 to $9.9 \mathrm{~g} / \mathrm{dL}$ as moderately and below $7 \mathrm{~g} / \mathrm{dL}$ as severely anaemic. ${ }^{14}$

\section{Data Analysis}

The analysis was done with original variables provided in the DHS datasets except for some variables where recoding was done for the convenience of interpretation e.g. type of anaemia. The data analysis was performed in SPSS version 22. The results are presented in the articles as proportions, mean, tables and bar diagrams, Test of significance determined by Pearson's chi square test. Multinomial 
regression analysis for the dependent variable type of anaemia performed for showing odds of association with independent variables. The pattern of association of anaemia and no anaemia with other variables in the major States of India was determined by cross tabulation and test of significance by Pearson's chi square test.

\section{RESULTS}

Out of a total of 6,99,686 women respondents, 32,428 (4.6\%) were pregnant at the time of survey.

\section{Distribution of Respondents According to Socio- Demographic Profile}

The mean age of pregnant women was 24.7 years \pm 4.874 . Majority (72.7 percent) women were in the age group 20-29 years, 11.4 percent and 16 percent in age groups 15-19 and 30 years and above respectively. The distribution of pregnant women according to the place of residence were 75.9 percent from rural and 24.1 percent from urban areas. Majority women (71.7 percent) belonged to Hindu while 16.2 percent were Muslim, 7.8 percent Christian, 1.8 percent Sikhs and 2.4 percent belonged to others; 79.9 percent belonged to any caste, 16.0 percent tribes, 4.0 percent either mentioned no caste/tribe or don't know. Of the 32428 pregnant women, 25.1 percent had no education, 13.2 percent with primary, 49.6 percent had secondary and 12.1 women had higher education. By wealth index, majority 47.2 percent were in the poorest and poorer quintile, 20.3 percent in middle and 32.5 percent in richer, richest quantile. Majority (36.3 percent) households have 6 to 9 members, 34.3 percent 4 to 5 members, 19.2 percent 2 to 3 members and 10.2 percent has 10 and more members. 59.2 percent of respondents have mosquito nets for sleeping. Only 5.3 percent slept under treated mosquito bed nets, 72.2 percent did not sleep under bed nets last night.

Amongst the total respondent families in 48.3 percent there were sanitary toilet facility available, 39.7 percent practiced open field defaecation and in remaining 4.5 percent the excreta disposal was by insanitary method, 7.5 percent of interviewee were not a de jure resident. Out of total user of sanitary toilet, 78.2 percent were from urban and 38.7 percent from rural areas. The practice of open field defaecation was more in rural (48.5 percent) compared to urban areas (11.7 percent).

\section{Fertility Profile of Women and Their Contraceptive Practice}

Out of total 32,428 pregnant women, in 39.03 percent there was no child ever born. Of the women with children ever born, in 58.6 percent the interval between marriage and $1^{\text {st }}$ birth was within 2 years, 19.5 percent between 2 to 3 years, 13 percent 3 to 5 years, 5.5 percent 5 to 10 years and 1.3 percent more than 10 years respectively. During the period in last 3 to 5 years before the present survey, 15,580 (48.0 percent) woman had no births, 37.4 percent with single child, 13.1 percent 2 child, 1.4 percent had 3 and more no of children. In 96.0 percent women there was no birth in the past year, 3.9 percent single birth and 0.05 percent more than one. The average age at $1^{\text {st }}$ birth was 20.9 years \pm 3.383 . Among all women 14.1 percent woman ever had history of a terminated pregnancy

The contraceptive usage among the pregnant woman were used in only 19.6 percent cases and in 80.4 percent they never used. Majority 12.2 percent used after birth of 1 st child, 2.9 percent having no births, 2.9,1.0 and 0.6 percent after 2nd, 3rd, 4+ number of births respectively. The use of family planning methods among pregnant women is less comparative to the national contraceptive prevalence rate (CPR) value of 56 percent among women in reproductive age groups. This is because in the present analysis 69.9 percent women were having no or only 1 child and 30.1 percent with birth order 2 and more in contrast to 25.7 percent and 74.2 percent in respective couple group in total women in the reproductive group of 15-45 years age. 15

71.6 percent women received IFA tablet during the last pregnancy, 28.1 percent did not and 0.3 percent don't know.

\section{Prevalence of Anaemia among Pregnant and Non- Pregnant Group- All India}

The haemoglobin estimation data was available for $6,84,911$ ( 97.9 percent) respondents out of the total 6,99,686 women. The prevalence of anaemia among the pregnant and nonpregnant groups. There is significant difference observed between the two groups (Pearson's chi square value= $6300.564 \mathrm{p}$ - value $=0.000$ ).

\section{Anaemia Prevalence among Pregnant Women- India}

Out of the total 32,428 pregnant women haemoglobin estimation value was available for 31,848 cases and remaining 580 were missing data. Of the 31,848 pregnant women, 1.4 percent were severely anaemic, 24.5 percent moderately, 23.7 percent mild anaemic and remaining 50.4 percent were without anaemia.

IV A. Haemoglobin among Different Age Groups

The Boxplot shows the different haemoglobin levels in different age groups [figure-1].

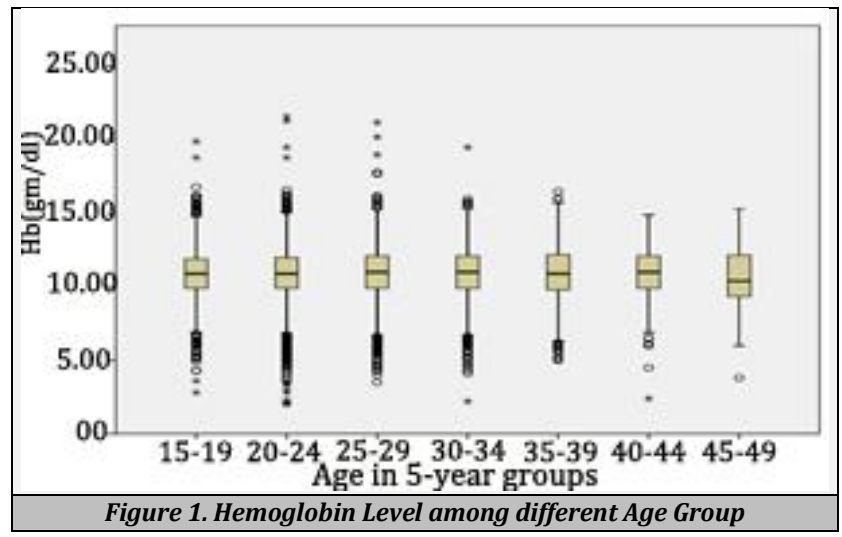

In the following sections anaemia prevalence among pregnant women has been described in relation to sociodemographic and maternal factors. 


\begin{tabular}{|c|c|c|c|c|c|c|}
\hline & ڤัँ & 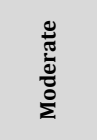 & $\overline{\underline{z}}$ & 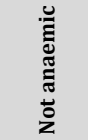 & 坖 & 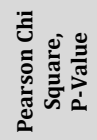 \\
\hline \multicolumn{7}{|c|}{ Type of Residence } \\
\hline Urban & $\begin{array}{c}86 \\
(1.14)\end{array}$ & $\begin{array}{c}1636 \\
(21.59)\end{array}$ & $\begin{array}{c}1716 \\
(22.65)\end{array}$ & $\begin{array}{c}4138 \\
(54.62)\end{array}$ & 7576 & 81.413 \\
\hline Rural & $\begin{array}{c}375 \\
(1.54)\end{array}$ & $\begin{array}{c}6175 \\
(25.44)\end{array}$ & $\begin{array}{c}5818 \\
(23.97)\end{array}$ & $\begin{array}{c}11904 \\
(49.04)\end{array}$ & 24272 & 0.000 \\
\hline \multicolumn{7}{|c|}{ Highest Level of Education } \\
\hline No education & $\begin{array}{c}178 \\
(2.22)\end{array}$ & $\begin{array}{c}2469 \\
(30.74)\end{array}$ & $\begin{array}{c}1996 \\
(24.85)\end{array}$ & $\begin{array}{c}3390 \\
(42.20)\end{array}$ & 8033 & 541.238 \\
\hline Primary & $\begin{array}{c}76 \\
(1.80)\end{array}$ & $\begin{array}{c}1136 \\
(26.87)\end{array}$ & $\begin{array}{c}972 \\
(23.00)\end{array}$ & $\begin{array}{c}2043 \\
(48.33)\end{array}$ & 4227 & 0.000 \\
\hline Secondary & $\begin{array}{c}180 \\
(1.14)\end{array}$ & $\begin{array}{c}3552 \\
(22.50)\end{array}$ & $\begin{array}{c}3781 \\
(23.95)\end{array}$ & $\begin{array}{c}8277 \\
(52.42)\end{array}$ & 15790 & \\
\hline Higher & $\begin{array}{c}27 \\
(0.71)\end{array}$ & $\begin{array}{c}654 \\
(17.22)\end{array}$ & $\begin{array}{c}785 \\
(20.67)\end{array}$ & $\begin{array}{c}2332 \\
(61.40)\end{array}$ & 3798 & \\
\hline \multicolumn{7}{|c|}{ Religion } \\
\hline Hindu & $\begin{array}{c}338 \\
(1.48)\end{array}$ & $\begin{array}{c}5796 \\
(25.33)\end{array}$ & $\begin{array}{c}5566 \\
(24.33)\end{array}$ & $\begin{array}{r}11179 \\
(48.86)\end{array}$ & 22879 & 271.479 \\
\hline Muslim & $\begin{array}{c}85 \\
(1.66)\end{array}$ & $\begin{array}{c}1315 \\
(25.74)\end{array}$ & $\begin{array}{c}1180 \\
(23.10)\end{array}$ & $\begin{array}{c}2528 \\
(49.49)\end{array}$ & 5108 & 0.000 \\
\hline Christian & $\begin{array}{c}20 \\
(0.80)\end{array}$ & $\begin{array}{c}387 \\
(15.50)\end{array}$ & $\begin{array}{c}497 \\
(19.91)\end{array}$ & $\begin{array}{c}1592 \\
(63.78)\end{array}$ & 2496 & \\
\hline Sikh & $\begin{array}{c}1 \\
(0.17)\end{array}$ & $\begin{array}{c}120 \\
(20.27)\end{array}$ & $\begin{array}{c}126 \\
(21.28)\end{array}$ & $\begin{array}{c}345 \\
(58.28)\end{array}$ & 592 & \\
\hline $\begin{array}{l}\text { Buddhist/Neo- } \\
\text { Buddhist }\end{array}$ & $\begin{array}{c}15 \\
(4.48)\end{array}$ & $\begin{array}{c}87 \\
(25.97)\end{array}$ & $\begin{array}{c}78 \\
(23.28)\end{array}$ & $\begin{array}{c}155 \\
(46.27)\end{array}$ & 335 & \\
\hline Other & $\begin{array}{c}2 \\
(0.46)\end{array}$ & $\begin{array}{c}106 \\
(24.20)\end{array}$ & $\begin{array}{c}87 \\
(19.86)\end{array}$ & $\begin{array}{c}243 \\
(55.48)\end{array}$ & 438 & \\
\hline \multicolumn{7}{|c|}{ Wealth Index } \\
\hline Poorest & $\begin{array}{c}142 \\
(1.87)\end{array}$ & $\begin{array}{c}2246 \\
(29.59)\end{array}$ & $\begin{array}{c}1925 \\
(25.36)\end{array}$ & $\begin{array}{c}3278 \\
(43.18)\end{array}$ & 7591 & 489.267 \\
\hline Poorer & $\begin{array}{c}131 \\
(1.74)\end{array}$ & $\begin{array}{c}2022 \\
(26.88)\end{array}$ & $\begin{array}{c}1799 \\
(23.91)\end{array}$ & $\begin{array}{c}3571 \\
(47.47)\end{array}$ & 7523 & 0.000 \\
\hline Middle & $\begin{array}{c}95 \\
(1.46)\end{array}$ & $\begin{array}{c}1495 \\
(23.04)\end{array}$ & $\begin{array}{c}1575 \\
(24.27)\end{array}$ & $\begin{array}{c}3325 \\
(51.23)\end{array}$ & 6490 & \\
\hline Richer & $\begin{array}{c}64 \\
(1.17)\end{array}$ & $\begin{array}{c}1226 \\
(22.47)\end{array}$ & $\begin{array}{c}1194 \\
(21.88)\end{array}$ & $\begin{array}{c}2973 \\
(54.48)\end{array}$ & 5457 & \\
\hline Richest & $\begin{array}{c}29 \\
(0.61)\end{array}$ & $\begin{array}{c}822 \\
(17.17)\end{array}$ & $\begin{array}{c}1041 \\
(21.75)\end{array}$ & $\begin{array}{c}2895 \\
(60.48)\end{array}$ & 4787 & \\
\hline \multicolumn{7}{|c|}{ Total Children ever Born } \\
\hline 0 & $\begin{array}{c}162 \\
(1.31)\end{array}$ & $\begin{array}{c}2583 \\
(20.88)\end{array}$ & $\begin{array}{c}2816 \\
(22.76)\end{array}$ & $\begin{array}{c}6809 \\
(55.04)\end{array}$ & 12370 & 321.208 \\
\hline 1 & $\begin{array}{c}121 \\
(1.22)\end{array}$ & $\begin{array}{c}2445 \\
(24.75)\end{array}$ & $\begin{array}{c}2401 \\
(24.30)\end{array}$ & $\begin{array}{c}4912 \\
(49.72)\end{array}$ & 9879 & 0.000 \\
\hline 2 & $\begin{array}{c}72 \\
(1.42)\end{array}$ & $\begin{array}{c}1415 \\
(27.81)\end{array}$ & $\begin{array}{c}1196 \\
(23.51)\end{array}$ & $\begin{array}{c}2405 \\
(47.27)\end{array}$ & 5088 & \\
\hline 3 & $\begin{array}{c}49 \\
(2.12)\end{array}$ & $\begin{array}{c}659 \\
(28.55)\end{array}$ & $\begin{array}{c}596 \\
(25.82)\end{array}$ & $\begin{array}{c}1004 \\
(43.50)\end{array}$ & 2308 & \\
\hline 4 & $\begin{array}{c}57 \\
(2.59)\end{array}$ & $\begin{array}{c}709 \\
(32.18) \\
\end{array}$ & $\begin{array}{c}525 \\
(23.83) \\
\end{array}$ & $\begin{array}{c}912 \\
(41.40) \\
\end{array}$ & 2203 & \\
\hline \multicolumn{7}{|c|}{$\begin{array}{l}\text { Table 1. Association of Anaemia with Various } \\
\text { Socio-Demographic Variables }\end{array}$} \\
\hline
\end{tabular}

IV B. Association of Anaemia with Various Sociodemographic Variables [Table-1]

From Table-1, there is significant association observed between type of anaemia prevalence and various sociodemographic variables. 54.62 percent of women were found not anaemic in urban areas in contrast to 49.04 percent in the rural areas. 2.22 percent women with no education were severely anaemic compared to 0.71 percent women with higher education. Among the different religious groups, women belonging to Christian religion were found to less suffer from anaemia 63.78 percent in contrast to 48.86 percent and 49.49 percent among Hindu and Muslim religion respectively. The women belonging to Muslim religion have slightly higher prevalence of severe/moderate anaemia compared to women in Hindu religion 1.66 percent/25.74 percent and 1.48 percent/25.33 percent respectively. The women who belonged to the poorest wealth index were 1.87 percent, 29.59 percent, 25.36 percent and 43.18 percent severely, moderately, mild and not anaemic in contrast with 0.61 percent, 17.17 percent, 21.75 percent and 60.48 percent among women belonging to the richest wealth index respectively. With increasing order of children ever born to women there is also increasing prevalence of different types of anaemia was observed e.g. 1.31 percent women with no children have severe anaemia compared to 2.59 percent with 4 and more children and also 55.04 percent and 41.40 percent not anaemic in the two groups respectively.

IV C. Duration of Pregnancy and Severity of Anaemia From Table-2 it is evident that with advancement of duration of pregnancy the severity of anaemia is increased and the association is found to be highly significant (Chi square $=761.957$; $p$-value-0.000)

\begin{tabular}{|c|c|c|c|c|}
\hline $\begin{array}{l}\text { Duration of } \\
\text { Pregnancy }\end{array}$ & Severe & Moderate & Mild & Not Anaemic \\
\hline $\begin{array}{c}\text { 1st Trimester } \\
(\mathrm{n}=9484)\end{array}$ & $\begin{array}{c}95 \\
(1.0)\end{array}$ & $\begin{array}{l}1550 \\
(16.3)\end{array}$ & $\begin{array}{c}2041 \\
(21.5)\end{array}$ & $\begin{array}{c}5798 \\
(61.1)\end{array}$ \\
\hline $\begin{array}{c}\text { 2nd Trimester } \\
\quad(\mathrm{n}=12732)\end{array}$ & $\begin{array}{l}188 \\
(1.5)\end{array}$ & $\begin{array}{l}3406 \\
(26.8)\end{array}$ & $\begin{array}{l}3254 \\
(25.6)\end{array}$ & $\begin{array}{c}5884 \\
(46.2)\end{array}$ \\
\hline $\begin{array}{l}\text { 3rd Trimester } \\
\quad(\mathrm{n}=9625)\end{array}$ & $\begin{array}{l}178 \\
(1.8)\end{array}$ & $\begin{array}{l}2854 \\
(29.7)\end{array}$ & $\begin{array}{l}2238 \\
(23.3)\end{array}$ & $\begin{array}{l}4355 \\
(45.2)\end{array}$ \\
\hline $\begin{array}{c}\text { Total } \dagger \\
(\mathrm{n}=31841)\end{array}$ & $\begin{array}{c}461 \\
(1.4)\end{array}$ & $\begin{array}{l}7810 \\
(24.5)\end{array}$ & $\begin{array}{r}7533 \\
(23.7)\end{array}$ & $\begin{array}{l}16037 \\
(50.4)\end{array}$ \\
\hline \multicolumn{5}{|c|}{$\begin{array}{c}\text { Table 2. Distribution of Women According to } \\
\text { Duration of Pregnancy and Severity of Anaemia }\end{array}$} \\
\hline
\end{tabular}

IV D. No. of Births in the Last 5 Years and Severity of Anaemia

With increasing birth order during the last 5 years there is increase in prevalence of moderate and severe anaemia compared to women not having child or single child and the association is found to be statistically significant Chi square=378.836; p-value-0.000.

\section{Anaemia Prevalence among Pregnant Women- In States and Union Territories of India}

There is variation in anaemia prevalence among the pregnant women in different States of India. The distribution of mean haemoglobin level among the different States and analysis of associated factors are explored in the following sections.

\section{Mean Haemoglobin Level and Types of Anaemia in States of India}

The mean haemoglobin level in India is $10.9 \mathrm{~g} / \mathrm{dL}$.[Figure-1] Of the 30 states and 6 union territories (UTs), the mean haemoglobin level in 3 UTs and 11 states are $<10.9 \mathrm{~g} / \mathrm{dL}, 6$ states are of same national value $10.9 \mathrm{~g} / \mathrm{dL}, 17$ states namely Meghalaya, Karnataka, Tamil Nadu, Chhattisgarh, Assam, Delhi, Punjab, Lakshadweep, Daman and Diu, Puducherry, Nagaland, Mizoram, Arunachal Pradesh, Manipur, Kerala, Sikkim have haemoglobin level $11.0 \mathrm{~g} / \mathrm{dL}$ and above. Among the states, in rural areas the lowest haemoglobin level observed in Dadra and Nagar Haveli $9.8 \mathrm{~g} / \mathrm{dL}$ and maximum in Sikkim $12.0 \mathrm{~g} / \mathrm{dL}$. In Urban areas, Andaman and Nicobar Islands have the minimum value $9.8 \mathrm{~g} / \mathrm{dL}$ and maximum in Kerala $12.0 \mathrm{~g} / \mathrm{dL}$ while the mean haemoglobin level in urban 
areas for India is $11.0 \mathrm{~g} / \mathrm{dL}$. There is differences observed in States according to type of residence. The State wise type of anaemia prevalence according to severity is given in Figure-2.

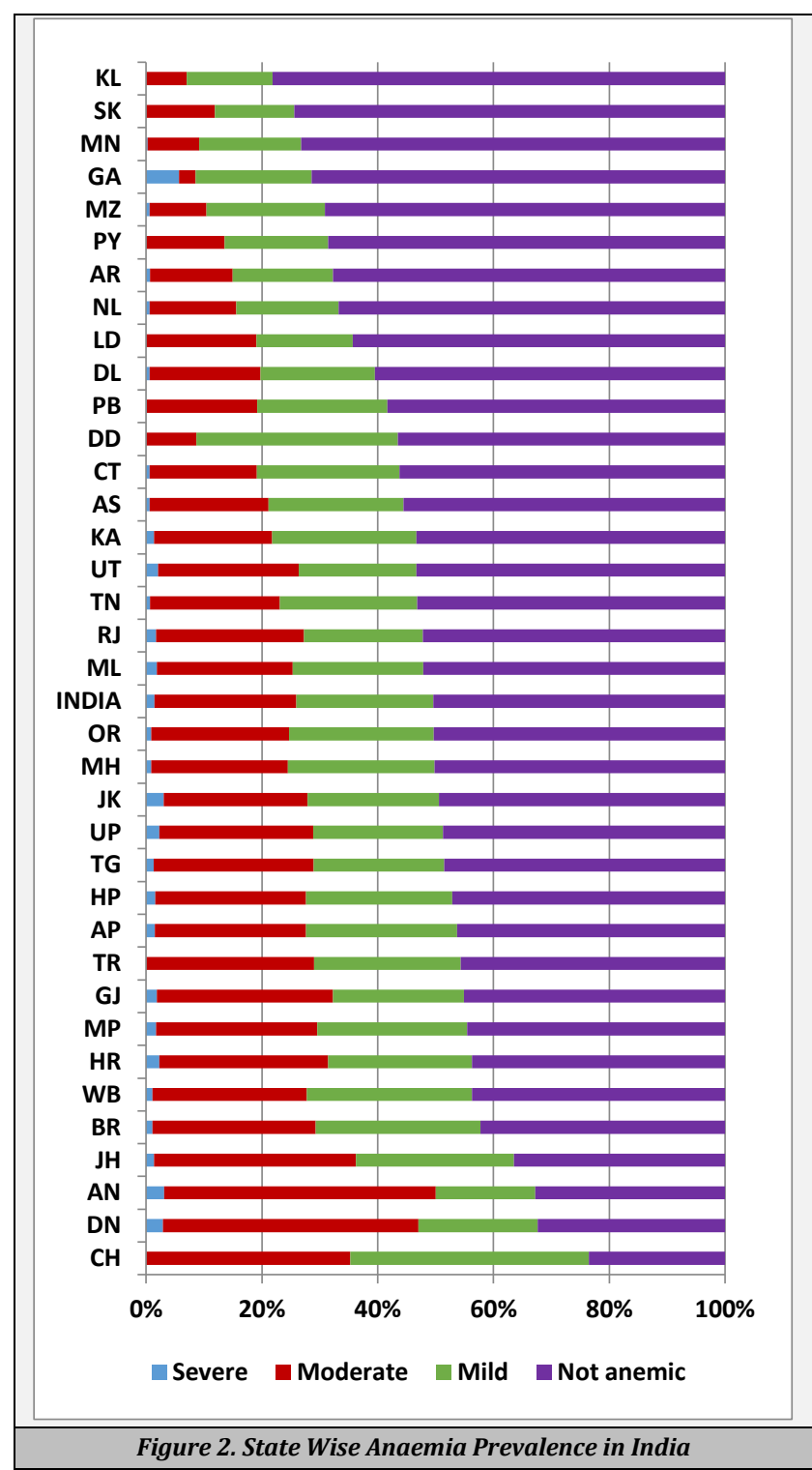

VI. Multinomial Regression Analysis and Odds Ratio for Selected Variables for the Dependant Variable Type of Anaemia.

From Table-3, it is observed that the women in poorest wealth index were having 1.216 times more prevalence of mild and 1.477 times moderate to severe anaemia in reference to women in the richest wealth index quintile. The pregnant women having no children in last 3 years were $74 \%$ less probable to suffer from moderate to severe anaemia in comparison with women having 2 children and more. Similarly, significant association in prevalence of anaemia found according to the religion, women belonging to Christian religion were $75 \%$ and $50 \%$ less likely to suffer from mild and moderate to severe anaemia as compared to in other religious groups. Those women with no children ever born were $74 \%$ and $66 \%$ less likely to have mild and moderate to severe anaemia respectively compared to women with children ever born and the association was highly significant. The families of pregnant women using sanitary toilets were $91 \%$ and $86 \%$ less chance to have mild and moderate to severe anaemia as compared with families practicing open field defaecation and this was also found to be highly significant. There was significant association observed between anaemia and women educational status, women with no education were 1.313 and 1.640 times more likely to suffer from mild and moderate to severe anaemia respectively as compared to women in the higher educational level.

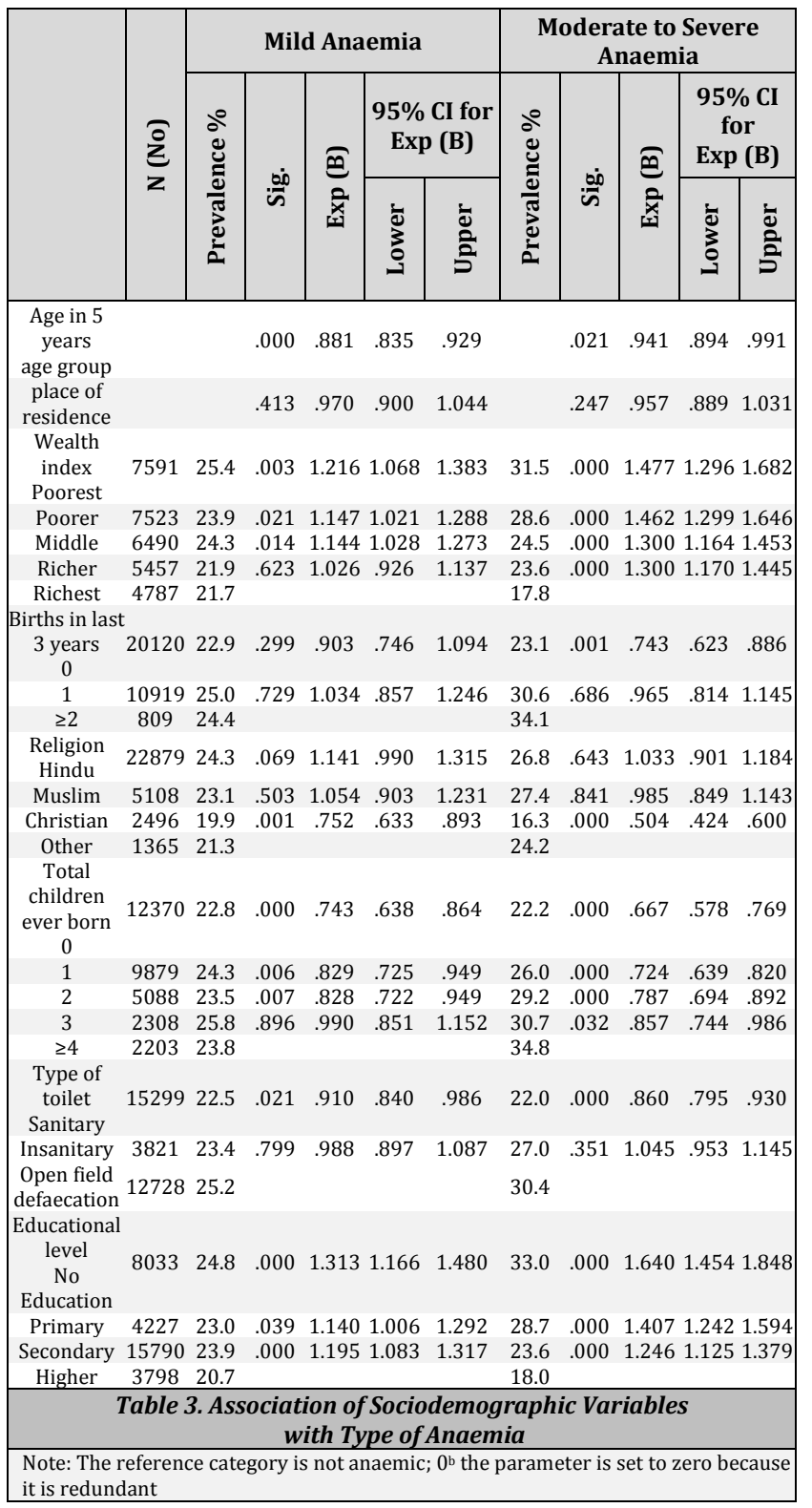

VII. Analysis of Factors for Pattern of Distribution of Anaemia in Major States of India

Cross tabulation of anaemia level and Major States of India with respect to different socio demographic variables in the respective categories were prepared and test of significance was obtained by using Pearson's chi square test. For facilitation of data analysis recoding of new variables were done where necessary and was grouped in to with anaemia and without anaemia.

From Section-IVB and VI, it has been observed that there is significant association between different socioeconomic variables with anaemia prevalence at the national level. 
However, there is interstate variation. For the present analysis, 19 major States were conveniently selected for finding the level of significance among the different socioeconomic variables and is presented in Table- 6 . Of the total 19 States, the educational level was found significantly associated in 15 States except in Maharashtra, Jammu and Kashmir, Andhra Pradesh and Kerala. Similarly, except the 9 States namely West Bengal, Gujarat, Jharkhand, Tamil Nadu, Delhi, Andhra Pradesh and Kerala, in remaining 10 States there was significant association observed between number of children ever born to women and prevalence of anaemia. The place of Residence was found significantly associated in 5 States- Tamil Nadu, Madhya Pradesh, Chhattisgarh, Punjab, Jharkhand while religion was found associated in 5 StatesHaryana, Jammu \& Kashmir, Jharkhand, Rajasthan and Punjab. The pattern of contraceptive use was found to be significantly associated in only 2 states namely Jammu and Kashmir, Chhattisgarh. In majority of 17 states there was significant association of wealth index to anaemia prevalence except in Delhi and Andhra Pradesh. The number of children born in last 3 years was found to be significantly associated in 11 States and in remaining states namely Jammu and Kashmir, West Bengal, Karnataka, Delhi, Chhattisgarh, Kerala, Andhra Pradesh and Jharkhand there was no significant association found.

\section{DISCUSSION}

Anaemia is the most common nutritional deficiency disorder in the world. About half of the global maternal deaths due to anaemia occur in South Asian countries; India contributes to about 80 per cent of the maternal deaths due to anaemia in South Asia. ${ }^{16}$ WHO has estimated that prevalence of anaemia in pregnant women is 14 per cent in developed and 51 per cent in developing countries and 65-75 per cent in India. ${ }^{17}$ According to NFHS 4 the prevalence of anaemia among pregnant women is 50.3 percent which is reduced from earlier 57.9 percent in NFHS 3 conducted in 2005-06.18 Despite considerable economic and scientific advancement during recent decades, there has been, at best, only marginal reduction in the global prevalence of anaemia. ${ }^{1}$

Previous global estimates made by DeMaeyer in 1985 indicated that approximately $30 \%$ of the world's population was anaemic. In 1992, WHO estimates for the year 1988 indicated that $37 \%, 51 \%$, and $35 \%$ of all women and pregnant and non-pregnant women were anaemic. ${ }^{19}$ From a systemic review and meta-analysis study the Prevalence of anaemia was estimated from 28 recent surveys and 25 countries with a pooled prevalence of $42.7 \%$ (95\% CI: $37.0 \%$, 48.4\%) in low- and middle-income countries, South Asian region (48.6\%; 95\% CI: 44.7\%, 52.4\%). ${ }^{20}$

The results from a systemic analysis of national surveys reveals that only $25 \%$ and $37 \%$ of all anaemia is associated with iron deficiency in pre-school children and non-pregnant women of reproductive age, respectively. ${ }^{21}$ There is incorrect assumption that everyone with anaemia is iron deficient (because anaemia tests measure haemoglobin levels), failing to account for the various causes of anaemia (e.g. infections, malaria, helminths, haemoglobinopathies and other micronutrient deficiencies). ${ }^{22}$ Variations in rates of anaemia may be due to methods used for surveying and assessing $\mathrm{Hb}$ levels. ${ }^{23} \mathrm{Hb}$ concentration is the most reliable indicator of anaemia at the population level, in populations where the prevalence of inherited haemoglobinopathies is high, the mean level of $\mathrm{Hb}$ concentration may be lowered. The causes of anaemia need to be identified considering that they may vary according to the population. ${ }^{1}$

In a study in Malawi 11 of 767 pregnant women the prevalence of mild anaemia was found to be 22.2 percent which is similar to 23.7 percent in the present NFHS 4 finding. However, there is higher prevalence of Moderate to severe anaemia of 25.9 percent is found in NFHS 4 findings in contrast to 11.9 percent in the same study.

The Nutrition Decade provides an enabling environment such that national, regional and international policies and programmes respect, protect and fulfil "the right of everyone to have access to safe, sufficient, and nutritious food, consistent with the right to adequate food, the fundamental right of everyone to be free from hunger consistent with the International Covenant on Economic, Social and Cultural Rights and other relevant United Nations instruments".

As per data NFHS 4, anaemia prevalence among pregnant women aged $15-49$ years recorded as $50.3 \%$ has declined from $57.9 \%$ in NFHS 3 . There is interstate variation in the anaemia prevalence varying from $22.6 \%$ in Kerala to $62.6 \%$ in Jharkhand. The improvements possibly have been because of increase in consumption iron folic acid for 100 days or more from $15.2 \%$ to $30.3 \%$ by the mothers who were pregnant. Among the states also there is variation in IFA consumption as reported to be as low as 8.3 percent in Arunachal Pradesh and highest 67.4 percent in Goa There is significant difference in anaemia prevalence between urban and rural areas.

The iron deficiency during pregnancy render the offspring more vulnerable for developing iron deficiency and anaemia right from infancy and thus there is an intergenerational self-perpetuating vicious cycle of anaemia in Indian population.

\section{CONCLUSIONS}

The present observation will add to our knowledge and to design interventions addressing the different sociocultural factors in diverse population groups. The promotion of adolescence health, access to quality antenatal services and effective interpersonal communications by village level functionaries will increase acceptability of anaemiaprevention services among women in the reproductive age group. The present study need more evaluation at state level with representative sample of different population groups for evaluating the associated factors of anaemia. There is a need to improve nutrition of girls starting at a young age for better pregnancy-related and early-child-health outcomes. 


\section{REFERENCES}

[1] Benoist BD, McLean E, Egli I, et al. Worldwide prevalence of anaemia 1993-2005: WHO global database on anaemia. World Health Organization, 2008.

[2] Global Health Observatory, 2017. http://apps.who.int/gho/data/node.main.ANAEMIAWO MEN?lang=en.

[3] World Health Organization /UNICEF/UNU. Iron Deficiency Anaemia: Assessment, Prevention and Control. A Guide for Programme Managers. Geneva, Switzerland: World Health Organization, 2001.

[4] Md. Mizanur R, Sarah KA, Md. Shafiur R, et al. Maternal anemia and risk of adverse birth and health outcomes in low- and middle-income countries: systematic review and meta-analysis. The American Journal of Clinical Nutrition 2016;103(2):495-504.

[5] Stoltzfus RJ. Iron deficiency: global prevalence and consequences. Food Nutr Bull 2003;24(Suppl 4):S99103.

[6] India State-Level Disease Burden Initiative Malnutrition Collaborators. The burden of child and maternal malnutrition and trends in it indicators in the States of India: The Global Burden of Disease study 1990-2017. The Lancet Child \& Adolescent Health 2019;3(12):85570 .

[7] India State-Level Disease Burden Initiative Collaborators. Nations within a nation: variations in epidemiological transition across the states of India, 1990-2016 in the Global Burden of Disease Study. Lancet 2017;390(10111):2437-60.

[8] Balarajan Y, Ramakrishnan U, Ozaltin E, et al. Anaemia in low-income and middle-income countries. Lancet 2011;378(9809):2123-35.

[9] NITI Aayog, Government of India. Nourishing India: National Nutrition Strategy. NITI Aayog, 2017. http://niti.gov.in/writereaddata/files/document_public ation/ Nutrition_Strategy_Booklet.pdf

[10] Kalaivani K, Ramachandran P. Time trends in prevalence of anaemia in pregnancy. Indian $J$ Med Res 2018;147(3):268-77.
[11] Adamu AL, Crampin A, Kayuni N, et al. Prevalence and risk factors for anemia severity and type in Malawian men and women: urban and rural differences. Population Health Metrics 2017;15(1):12.

[12] Rutstein SO, Johnson K. The DHS wealth index. DHS Comparative Reports No. 6. Calverton (MD): ORC Macro, 2004.

http://www.dhsprogram.com/publications/publicationcr6-comparative-reports. cfm

[13] IIPS. National Family Health Survey 2015-16 (NFHS-4): Clinical Anthropometric Biochemical (Cab) Manual, December 2014.

[14] World Health Organisation. Haemoglobin concentrations for the Diagnosis of Anaemia and Assessment of Severity of Anaemia. Geneva: WHO, 2011. [http://www.who.int/vmnis/indicators//haemoglobin/ en/]

[15] Dey AK. Socio-demographic determinants and modern family planning usage pattern-an analysis of National Family Health Survey-IV data. Int J Community Med Public Health 2019;6(2):738-49.

[16] Ezzati M, Lopez AD, Rodgers A, et al. Selected major risk factors and global and regional burden of disease. Lancet 2002;360(9343):1347-60.

[17] De Mayer E, Adiels-Tegman M. Prevalence of anaemia in the World. World Health Organ Qlty 1985;38(3):302-16.

[18] International Institute for Population Sciences (IIPS) and ICF. 2017. National Family Health Survey (NFHS-4), 2015-16: India. Mumbai: IIPS.

[19] World Health Organization. The Prevalence of Anaemia in Women: a tabulation of available information. 1992. (WHO/MCH/MSM/92.2).

[20] Petry N, Olofin I, Hurrell RF, et al. The proportion of anemia associated with iron deficiency in low, medium, and high human development index countries: a systematic analysis of national surveys. Nutrients 2016;8(11):693.

[21] Global nutrition report 2018.

[22] Balasubramaniam P, Malathi A. Comparative study of hemoglobin estimated by Drabkin's and Sahli's methods. J Postgrad Med 1992;38(1):8-9.

[23] Kalaivani K. Prevalence \& consequences of anaemia in pregnancy. Indian J Med Res 2009;130(5):627-33. 